\title{
Liquid Democracy: Potentials, Problems, and Perspectives*
}

\author{
Christian BLUM \\ Philosophy, Rutgers University \\ and \\ Christina ISABel Zuber \\ Political Science, University of Konstanz
}

$\mathbf{T}$

HE first pirate party was founded in Sweden in 2006. Since then, many have followed the example, and the non-governmental organization Pirate Parties International (PPI) now counts members from 43 different countries. Pirate parties have gained seats in local, regional (e.g., Berlin, North Rhine-Westphalia, Saarland, Schleswig-Holstein), and national (Iceland, Czech Republic) parliaments, as well as the European Parliament. These parties are mostly known for opposing Internet censorship and defending transparency, civil rights, and open content. However, they are also suggesting a model of collective decision-making that seeks to remedy democratic systems from within, namely liquid democracy, a model they are already applying for intra-party decision-making. ${ }^{1}$ By combining direct democratic participation with a highly flexible model of representation, liquid democracy promises the best of both worlds: Citizens can freely choose to either vote directly on individual policy-issues, or to delegate their votes to issue-competent representatives who

\footnotetext{
*The original ideas for this paper were developed during a workshop on liquid democracy that was organized by the authors at the University of Cologne in spring 2012. We are indebted to all participants of the workshop, but in particular to Saskia Ruth, Holger Reinermann, and Gregor Zons for their contributions during the inspiring discussions we had. We would further like to thank René Röderstein for giving us the opportunity to present insights from the workshop to members of the Cologne Pirate Party and receive their feedback. Previous versions of this paper have been presented at the PDD Specialist Group Conference, 9-11 July 2014, Newcastle, England and at the $4^{\text {th }}$ Global International Studies Conference, 6-9 August 2014, Frankfurt am Main, Germany. We wish to thank Sergiu Gherghina, Bob Goodin, and three anonymous referees of the Journal of Political Philosophy for their excellent comments that have helped us improve this article. Both authors wish to acknowledge financial support received from the Fritz Thyssen Foundation while drafting the manuscript.

${ }^{1}$ See Pirate Parties International, “About the PPI," 2009; available at <http://www.ppinternational.net/about>; Anna Litvinenko, "Social media and perspectives of liquid democracy: the example of political communication in the Pirate Party in Germany," Proceedings of the 12th European Conference on eGovernment, ed. M. Gascó (Reading: Academic Publishing International, 2012), pp. 403-7; and Simon Franzmann, "Aufgespießt. Wie der Erfolg der Piratenpartei Gesellschaft, Politik und Politikwissenschaft herausfordert," Mitteilungen des Instituts für Deutsches und Internationales Parteienrecht und Parteienforschung, 18 (2012), 123-6.
} 
vote on their behalf. This delegation is policy-area specific and can be retracted instantly. ${ }^{2}$

So far, normative democratic theory appears to have neglected this model of democratic decision-making. The substantive idea was introduced into the academic debate by James C. Miller in 1969 under the somewhat unwieldy term of "a program for direct and proxy voting." ${ }^{3}$ Miller's work received very limited attention from contemporary authors with just one-rather skeptical-review that Martin Shubik dedicated to his proposal. ${ }^{4}$ Since the early 2000's, the model has been rediscovered and discussed alternatively under the terms liquid democracy, delegative democracy, or proxy voting. ${ }^{5}$ More recent contributions have added further detail to Miller's proposal and have aimed to defend liquid democracy with indirect and direct arguments. The indirect argument holds that liquid democracy comes closest to the ideal of complete direct democracy by "making compatible the better features of direct voting with the practical necessity of some representation." Direct arguments hold, first, that liquid democracy "improve[s] the legislature's performance" 7 by allowing members to select issue-competent delegates, rather than representatives who decide on all issues regardless of expertise. Second, it is "more democratic" 8 than its representative counterpart since the entitlement to either vote directly or to delegate votes enables members "to participate fully" ${ }^{\text {in }}$ in political decisions. However, the arguments have so far remained highly general in nature, and the authors have not pursued the aim of justifying liquid democracy explicitly based on criteria derived from normative democratic theory. ${ }^{10}$

We seek to fill this gap. We first define the basic model of liquid democracy through four properties: direct democracy, flexible delegation, meta-delegation, and instant recall. We then offer a democratic-theoretical justification of liquid democracy, understood as a procedure for democratic decision-making at the systemic level. ${ }^{11}$ Normative democratic theory claims that we can identify criteria

\footnotetext{
${ }^{2}$ See Bryan Ford, "Delegative democracy," unpublished manuscript, 2002; available at $<$ http:// www.brynosaurus.com/log/2002/0515-DelegativeDemocracy.pdf $>$.

${ }^{3}$ James C. Miller, "A program for direct and proxy voting in the legislative process," Public Choice, 7 (1960), 107-13, at p. 107.

${ }^{4}$ Martin Shubik, "On homo politicus and the instant referendum," Public Choice, 9 (1970), 79-84.

5See: Ford, "Delegative democracy"; Dan Alger, "Voting by proxy," Public Choice, 126 (2006), 1-26; and James Green-Armytage, "Direct voting and proxy voting," unpublished manuscript, 2014; available at <http://inside.bard.edu/ armytage/proxy.pdf $>$.

${ }^{6}$ Miller, "A program for direct and proxy voting," p. 107; see also Ford, "Delegative democracy," p. 1.

${ }^{7}$ Alger, "Voting by proxy," p. 9.

${ }^{8}$ Green-Armytage, "Direct voting and proxy voting," p. 6

${ }^{9}$ Ibid.

${ }^{10}$ In addition, Ford's "Delegative democracy" and Green-Armytage's "Direct voting and proxy voting" are draft manuscripts reflecting work in progress.

${ }^{11}$ The interaction between liquid democracy as a procedure for intra-party decision-making and an overall representative system is thus not the subject of this paper. We also set aside all normative issues implied by the practical application of liquid democracy through software tools such as
} 
in virtue of which some variants of collective decision-making are better than others. These criteria specify which primary function collective decision-making must fulfill, and they allow measuring the goodness of different variants of decision-making based on how well these variants fulfill that function. ${ }^{12}$ Two major competing accounts provide such criteria: the epistemic account and the equality-based account. They paint different and, arguably, incompatible pictures of what is at stake in decision-making and presuppose distinct notions of the common good. ${ }^{13}$ However, proponents of liquid democracy need not opt for one account. We argue that their basic model is preferable to representative democracy in terms of the criteria offered by both approaches: (1) liquid democracy mobilizes more political expertise than purely representative democracy; (2) liquid democracy is more egalitarian than representative democracy. We choose representative democracy as the normative benchmark because we follow Steffen Ganghof's argument that the justification of democratic institutions should be comparative, judging whether they can fulfill their purpose "more effectively and efficiently than the best alternative." 14

However, unlike representative democracy, liquid democracy puts high demands on ordinary members of the political community who are expected to select competent experts on the epistemic account and to choose representatives that best further their subjective interests on the equality-based account. We argue that social epistemology, collective intelligence, and the literature on voter competence provide grounds for optimism that they are likely to perform these tasks in a satisfying way.

In addition, liquid democracy encounters the challenges of (1) avoiding to recreate representative democracy's problem of two classes of citizens, though in a different way (the problem of unequal voting power) and (2) achieving consistency across the whole set of decisions being made across different policy areas (the problem of policy-inconsistency). We therefore suggest a modified account that combines liquid democracy with a trustee model of representation, requires decision-makers to adhere to deliberative norms, and balances liquid decision-making in legislatures with an executive that reviews the formal feasibility of policies and moderates package deals between proposals from different policy areas.

LiquidFeedback, including inter alia the problem of secret voting. These constitute important topics for future considerations.

${ }^{12}$ Unlike many authors writing about democratic theory, we prefer to use the basic normative notions "goodness" and "betterness" in this context, rather than "legitimacy," because we consider legitimacy to be a non-gradual property of political systems. On our reading, political systems are either legitimate or illegitimate, but never more or less legitimate than others. They can, however, be better or worse than others by degrees.

${ }^{13}$ See Christian Blum, 'Why the epistemic justification of deliberative democracy fails', Challenges to Democratic Participation, ed. Andre S. Campos and José Gomes André (Plymouth, MA: Lexington Books, 2014) pp. 47-65; at p. 56.

${ }^{14}$ Steffen Ganghof, "Equality-based comparison: how to justify democratic institutions in the real world," Politics, 33 (2013), 101-11, at p. 106 
The next section introduces the basic model of liquid democracy. Section II provides an epistemic justification of liquid democracy while section III defends liquid democracy applying the criteria of the equality-based account. Section IV argues that ordinary members of the political community can be expected to competently perform their liquid democratic tasks. Section V suggests modifications of the basic model in light of the problems of unequal voting power and policy-inconsistency. Section VI concludes the article and points to topics that should be addressed in the future.

\section{THE BASIC MODEL OF LIQUID DEMOCRACY}

Liquid democracy is a procedure for collective decision-making that combines direct democratic participation with a flexible account of representation. Its basic model consists of four components that can be stated as follows: All members of a political community that satisfy a set of reasonable participatory criteria (adulthood, baseline rationality) are entitled to:

(I) directly vote on all policy issues (direct democratic component);

(II) delegate their votes to a representative to vote on their behalf on (1) a singular policy issue, or (2) all policy issues in one or more policy areas, or (3) all policy issues in all policy areas (flexible delegation component);

(III) delegate those votes they have received via delegation to another representative (meta-delegation component $)^{15}$;

(IV) terminate the delegation of their votes at any time (instant recall component).

These specifications are best illustrated by an example. Consider a member $A$ who ponders on three upcoming policy decisions. The first decision concerns a bill that imposes stricter sanctions on tax dodgers in order to drastically reduce fiscal evasion in the future. According to (I), $A$ is entitled to directly vote on this issue; as luck would have it, she is an expert in this field (maybe she majored in tax law), and thus it seems natural that she would do so. The second decision is about the authorization to cultivate a genetically enhanced corn variety. $A$ has a keen environmental conscience, but possesses little knowledge about this policy area. However, she is closely acquainted with $B$ who is a renowned biologist with a background in bioethics. Since $A$ trusts $B$ 's judgment and (II) entitles her to delegate her vote to $B$, it seems sensible that she should authorize him to vote on her behalf on issues that pertain to environmental policy. As a consequence, $B$ now possesses two votes that he can bring to bear on the issue at hand: $A$ 's vote and his own. The third decision concerns a trading agreement with another country. A knows little about said country or about economic policy; and neither

\footnotetext{
${ }^{15}$ The meta-delegative component is not featured in Miller's original account. Ford added to the basic model (see Ford, "Delegative democracy," p. 10).
} 
is she acquainted with any expert in this field. However, she knows another member $C$ who is well connected with a number of specialists on international relations and economics. Since (II) entitles her to delegate her vote on this issue to $C$, and since (III) entitles $C$ to delegate $A$ 's vote to a further member of the community, $A$ would do well, it appears, to transfer her vote to $C$ with the express instruction that he transfer it to a specialist of his choosing. Once all decisions have been made, $A$ surveys the results. Doing so, she might unearth new information that cast doubts on whether $B$ has used her vote with her best interests in mind (maybe he was swayed in his decision by a lobby group). Realizing this, $A$ makes use of (IV) and terminates her representative relationship with $B$. Although this does not affect the previous decision, it deprives $B$ of $A$ 's voting power regarding future decisions.

The basic model of liquid democracy stands in stark contrast to the classical model of representative democracy. According to the latter, political decision-making proceeds in two stages: In the first stage, all members elect representatives-who compete for votes with different political programs-for a fixed term. In the second stage, the elected representatives directly vote on all policy issues at hand; and they do so with equal voting power. ${ }^{16}$ Thus, representative democracy divides the members of a political community into two political classes: On the one hand, there is the class of members who authorize other members to vote on policy issues on their behalf, but do not vote on policy issues themselves; this class is commonly labeled the class of principals. On the other hand, there is a group of members who are authorized by others to vote on their behalf on all issues, namely, the class of representatives.

We can begin delineating the differences by noting that, first, liquid democracy does not require members to be authorized via election in order to vote on policies. All members are entitled to vote on all policies irrespective of whether they represent other members. Second, it allows for area-specific representation-rather than representation with respect to all policy issues-such that members directly authorize experts to vote on their behalf with respect to a limited policy area; or indirectly authorize experts by conferring their vote to members who possess meta-expertise and can select experts to vote on their behalf. Third, it makes short shrift of turn-based representation by allowing principals to immediately retract their votes when their representatives have not voted to their satisfaction. Fourth, it allows that representatives can have unequal voting power, since their voting power is a function of the votes conferred upon them plus their own vote.

\footnotetext{
${ }^{16}$ For normative arguments in favor of combining proportional representation for selecting representatives with majority vote to decide on policy issues in legislative assemblies, see Steffen Ganghof, "Politische Gleichheit und echte Mehrheitsdemokratie. Über die normativen Grundlagen institutioneller Arrangements," Zeitschrift für Politikwissenschaft, 15 (2005), 741-63, drawing on Thomas Christiano, The Rule of the Many (Boulder, CO: Westview Press, 1996). We take this combination that Ganghof terms "real majoritarian democracy" as the model when referring to representative democracy.
} 


\section{THE EPISTEMIC JUSTIFICATION OF LIQUID DEMOCRACY}

The epistemic account of democracy is advocated, among others, by Carlos S. Nino, David M. Estlund, Fabienne Peter, Christian List and Philip Pettit, and Hélène Landemore. ${ }^{17}$ It is based on two premises that may be called the error premise and the epistemic premise:

(a) Error premise: the members of a political community can err about matters of the common good.

Members of a political community can err about matters of the common good and thus authorize political actions that are detrimental to their collective welfare. Causes for such errors are: lack of information, false information, inconsistent inferences drawn from correct information, or manipulation by agenda-setters. ${ }^{18}$ The possibility of erring about the common good presupposes objective normative standards that transcend the currently held interests of the members and that can be determined by truth-apt beliefs. ${ }^{19}$ If there were no such standards, it would be conceptually impossible that the realization of the members' currently held interests was ever detrimental to their collective welfare. These standards must be agentindependent and observer-independent, that is, their validity neither depends on the judgments or desires of those to whom they apply, nor on the judgments and desires of anyone in their environment. ${ }^{20}$ As expressed in the second premise, these standards allow assessing the goodness of political decision-making procedures:

(b) Epistemic premise: political decision-making procedures derive their goodness from reliably generating true beliefs about the common good.

This view is encapsulated in Estlund's claim that "it must count in favor of a social decision procedure that it tends to produce the better decision." ${ }^{21}$ In other

\footnotetext{
${ }^{17}$ Carlos S. Nino, The Constitution of Deliberative Democracy (New Haven, CT: Yale University Press, 1996); David M. Estlund, Democratic Authority (Princeton, NJ: Princeton University Press, 2008); Fabienne Peter, Democratic Legitimacy (New York: Routledge, 2009); Christian List and Philip Pettit, Group Agency (Oxford: Oxford University Press, 2011); and Hélène Landemore, Democratic Reason (Princeton, NJ: Princeton University Press, 2012).

${ }^{18}$ See Joseph A. Schumpeter, Capitalism, Socialism and Democracy (New York: Harper \& Row, 1976) and John S. Dryzek, Deliberative Democracy and Beyond (Oxford: Oxford University Press, 2002).

${ }^{19}$ See Estlund, Democratic Authority, p. 98.

${ }^{20}$ For a more detailed discussion see David Enoch, Taking Morality Seriously (Oxford: Oxford University Press, 2011), p. 10. We remain neutral on the material question of whether the common good is best construed via a so-called objective list account (i.e., as consisting of a set of intrinsically valuable goods), a constructivist account (i.e., as constituted by the hypothetical agreement of a group of fully informed and fully rational individuals), or some other account. On objective list accounts in ethics, see Thomas Hurka, Perfectionism (Oxford: Clarendon Press, 1993). On constructivist accounts, see Ronald Milo, "Contractarian constructivism," Journal of Philosophy, 94 (1995), 181-204. The important point is that the common good, as presupposed by the epistemic account, is an objective normative entity that members of the political community can either ascertain or fail to ascertain.

${ }^{21}$ Estlund, Democratic Authority, p. 98. In more technical terms: there ought to be a considerable above 0.5 probability that the collective decision-making procedure indicates $\mathrm{p}$ if $\mathrm{p}$ is true, and there ought to be a considerable above 0.5 probability that it does not indicate $\mathrm{p}$ if $\mathrm{p}$ is false (for a detailed discussion, see List and Pettit, Group Agency, pp. 81-103).
} 
words: It is irrational not to choose a system whose procedures are more reliable in generating knowledge about the common good than alternative systems. The central function of political procedures is then the identification of normative truths about what is good for a given society. Hence, the epistemic account provides the following criterion for assessing the goodness of different forms of decision-making procedures, namely: the greater the epistemic reliability of the procedure, the better the procedure.

How does liquid democracy fare on this account? We argue that it is more reliable in generating true beliefs about the common good and choosing corresponding policies than representative democracy because it has a greater capacity for mobilizing policy area expertise. A few words on the notion of policy area expertise and its relation to the reliability of decision-procedures: We hold that a member of a community has expertise with respect to a policy area if and only if (1) she has considerably more true beliefs and less false beliefs than the average member about which policies pertaining to that area are conducive to the common good and which are not; and (2) there is a considerable above average probability that she will form true beliefs and will not form false beliefs of the above-mentioned types in the future. Thus, the reliability of a decision-making procedure co-varies positively with its capacity for mobilizing policy area expertise. The more expertise can be brought to bear on policy decisions, the more likely is it that these decisions will advance the common good.

The first and main reason why liquid democracy has a greater capacity for mobilizing policy area expertise than its counterpart is that it allows for policy area specific representation. In a purely representative democracy, members must authorize representatives to vote on their behalf on all policy issues-regardless of their domains of expertise. Thus, it is highly likely that, on the one hand, votes will be negatively influenced by decision-makers' lack of expertise; and that, on the other hand, many members who possess more expertise on the issues at hand get no say. In short: Representative democracy with its one-size-fits-all model of representation has a tendency to include the wrong kind of decision-makers and exclude the right kind of decision-makers. ${ }^{22}$ By contrast, members in a liquid democracy can "handpick" representatives to vote exclusively on issues that fall into their domain of competence. Thus, it is far less likely that votes are cast by representatives who have no expertise that they can bring to bear on policy decisions. The second reason is that the instant recall provision allows for the

\footnotetext{
${ }^{22}$ It should be acknowledged that representative democracies also have mechanisms to mobilize policy area specific expertise, e.g., through specialized parliamentary committees and expert hearings. However, two important differences should be noted: First, comparative studies of parliamentary committees in Western Europe show that the power of parties and the prestige of the committee (i.e., factors unrelated to expertise) play the dominant role in appointment. See Erik Damgaard, "How parties control committee members," Parliaments and Majority Rule in Western Europe, ed. H. Döring (New York: St. Martin's Press, 1995), pp. 308-25. The committees are therefore affected by partisan biases. Second, in the case of expert hearings, experts are only advisors, not decision-makers, and their influence is conditioned by the willingness of MPs to take up their suggestions.
} 
replacement of experts whose track record proved suboptimal, by choosing more promising representatives. Consequently, it is possible to effectively and efficiently filter out the best experts without the time lags of electoral cycles.

We can summarize the argument as a logical inference: if (1) the goodness of political decision-making procedures is dependent on their reliability in generating true beliefs about the common good and choosing corresponding policies; and if (2) their reliability is dependent on their capacity for mobilizing policy area expertise; and if (3) liquid democracy has, due to its flexible delegation component and instant recall component, a greater capacity for mobilizing policy area expertise than representative democracy, then (4) liquid democracy is better than representative democracy. Since we believe that premises (1), (2), and (3) are plausible, we hold that on the epistemic account, liquid democracy is indeed superior to its counterpart.

\section{THE EGALITARIAN JUSTIFICATION OF LIQUID DEMOCRACY}

The equality-based account of democracy is advocated, among others, by Peter Singer, Jeremy Waldron, and Thomas Christiano. ${ }^{23}$ It is based on what may be called the sovereignty premise and the equality premise:

(c) Sovereignty premise: the members of a political community shape the welfare of their community on the basis of their own subjective interests.

Following this account, a political community's common good is not a normative entity that is "out there" waiting to be discovered, as proponents of the epistemic account would have it. Rather, its members are sovereign authors of their own welfare who have the last word on deciding what is good and bad for their community. ${ }^{24}$ Hence, their subjective interests are constitutive of and prior to the common good itself; and the positive value of a political action for the common good is a function of the valuing of that action by the members themselves. ${ }^{25}$

In light of the heterogeneity of interests in modern political communities, it is highly unlikely, though, that all members always agree on the content of the common good. This is where the second premise comes into play:

\footnotetext{
${ }^{23}$ Peter Singer, Democracy and Disobedience (Oxford: Oxford University Press, 1973); Jeremy Waldron, Law and Disagreement (Oxford: Oxford University Press, 1999); Thomas Christiano, The Rule of the Many; Christiano, "Knowledge and power in the justification of democracy," Australasian Journal of Philosophy, 79 (2001), 197-215; Christiano, "The authority of democracy," Journal of Political Philosophy, 12 (2004), 266-90; Christiano, The Constitution of Equality (Oxford: Oxford University Press, 2008).

${ }^{24}$ See Christian Blum, "Determining the common good: a (re-)constructive critique of the proceduralist paradigm," Phenomenology and Mind, 3 (2012), 176-88, at p. 180.

${ }^{25}$ Following David Sobel's standard account ("On the subjectivity of welfare," Ethics, 107 (1997), 501-8), we define subjective interests as intentional and prospective pro-attitudes that are directed towards states of affairs that are considered desirable by the bearers of those attitudes.
} 
(d) Equality premise: political decision-making procedures derive their goodness from allowing each member to assert her interests in an equal fashion.

Given that the members' subjective interests are constitutive of their collective welfare, it seems reasonable to assume that each member's interests ought to be given equal weight in determining the content of the common good. Christiano argues with great force for this assumption by stating that " $t]$ his equality proceeds from the importance of interests as well as the separateness of persons. ... no one's interests matter more than anyone else's." 26 Hence, the equality-based account provides the following criterion for assessing the goodness of different forms of decision-making procedures: the greater the participatory equality of the procedure, the better the procedure.

How does liquid democracy fare on the equality-based account? There are two respects in which liquid democracy facilitates a greater equality of participatory resources and is hence preferable to representative democracy. First, consider again the decision-making model of representative democracy. By design, the latter facilitates an unequal distribution of participatory resources insofar as its two stage decision-making process divides the community in two political classes (see section I): the class of principals, who only indirectly assert their interests by electing a representative or group of representatives whose policy proposals best match their own preferences; and the class of representatives who directly assert their interests by voting on policies. Liquid democracy remedies this inequality by introducing a direct democratic component, thus allowing all members-regardless of whether they act as representatives-to directly assert their interest by voting on all policy issues.

However, liquid democracy is not only more egalitarian in virtue of its direct democratic component. We argue that, second, the flexible delegation component also allows for a more egalitarian political representation than purely representative democracy. Consequently, even when members make use of representation (which they most likely will do on many occasions), they are better off in terms of participatory equality. To see why this is so, consider the fact that in a representative democracy principals must choose between preconceived bundles of policy goals proposed by candidates. It is highly unlikely that all principals can wholly identify with specific bundles proposed by candidates, that is, acknowledge them as completely representing their own interests. Rather, they will have to compromise by electing candidates whose bundles cover most of their political concerns and thus forsake the assertion of some of their interest. Furthermore, it is likely that some principals will have to compromise more than others: Some may find most of their interests represented by a specific bundle; others may only be able to identify with a singular aspect of a bundle or, indeed, by no aspect of any bundle whatsoever. Simply put, the capacities of principals to

\footnotetext{
${ }^{26}$ Christiano, "The authority of democracy," p. 269.
} 
indirectly assert their interests by electing representatives varies with respect to how well their interests match with the bundles of policy proposals offered by candidates; and this variance makes for an unequal distribution of participatory power.

The flexible delegation component of liquid democracy, on the other hand, allows all members-regardless of the combination of their interests-to select specific representatives for each of their political concerns. Since all members are entitled to authorize representatives to vote on their behalf with regard to a limited policy area, they can customize a set of representatives each of which represents a specific interest held by them. The more fine-grained account of political representation offered by liquid democracy makes redundant the need to compromise in the indirect assertion of interests. Consequently, it remedies the problem of unequal participatory power that is generated in representative democracy by differences between how well the different members' interests match with available policy bundles. ${ }^{27}$

We can, again, summarize the argument as a logical inference: if (1) the goodness of a political decision-making procedure is dependent on its participatory equality; and if (2) participatory equality is dependent on the equality of resources for directly asserting interests (via voting on policy issues) and for indirectly asserting interests (via authorizing representatives whose agendas match the interests of their principals); and if (3) liquid democracy facilitates a greater equality of resources with respect to both forms of asserting interests than representative democracy, then (4) liquid democracy is better than representative democracy. Since we believe that premises (1), (2), and (3) are plausible, we hold that on the equality-based account liquid democracy is superior to its counterpart.

\section{ARE ORDINARY MEMBERS OF THE POLITICAL COMMUNITY OVERBURDENED BY LIQUID DEMOCRACY?}

We have argued that liquid democracy is preferable to representative democracy on both major accounts of normative democratic theory. On the one hand, it allows members to delegate their votes to issue-competent experts (epistemic superiority). On the other hand, it allows them to vote directly on policy issues and to customize a set of representatives each of which represents a specific subjective interest held by them (egalitarian superiority). These advantages depend on whether members can competently perform a number of tasks: they must select the right expert for the right job; they must decide when their interests

\footnotetext{
${ }^{27}$ This shows that allowing for liquid democracy within political parties is already an important step towards greater equality since it allows individuals to influence the party's electoral program, thus helping to design a policy-bundle that comes closer to their individual interests.
} 
are better served by voting directly on a policy issue and when by delegation; and they must decide when to make use of the instant recall option.

However, one might call into question whether ordinary members are capable of performing these tasks. The informational demands placed on the individual in a liquid democracy appear to be much greater than those placed on a voter in a representative democracy, where no policy-area-specific knowledge is required and where representatives are elected for a fixed term. It seems that if a layperson with respect to a domain of expertise $E$ must decide whether to give credence to a putative expert $E_{1}$ or a rivaling putative expert $E_{2}$, she cannot acquire good epistemic reasons for favoring one over the other. ${ }^{28}$ For, to be in that position she would require expert knowledge about $\mathrm{E}$ herself, that is, knowledge that is unavailable to laypersons. This skeptical worry is particularly pressing with respect to the political sphere where citizens must navigate a vast spectrum of distinct policy areas that are characterized by steep expert-layperson gaps.

In the following, we argue that it is nonetheless plausible to expect members of a political community to perform their liquid democratic tasks, both individually, and, perhaps more importantly, as a collective. First, social epistemology provides good reasons for holding on to the general claim that laypersons can make reasoned choices between conflicting putative experts. Second, arguments from collective intelligence show (1) that collective epistemic systems (such as the World Wide Web) can support reasoned expert selection through practices of ranking and rating, and (2) that if sufficiently diverse, the collective of people in a liquid democracy can produce better decisions even if reasoned expert selection fails. Third, empirical studies of voter competence in direct democratic decision-making show that even the poorly informed make reasoned choices.

Theorists of social epistemology argue that there are several sources of evidence that laypersons can bring to bear on the evaluation of putative experts without having to become experts themselves. ${ }^{29}$ The first source of evidence concerns the performance of putative experts in discussions. When following a discussion between $E_{1}$ and $E_{2}$ a layperson may not be able to assess the content of the arguments advanced by the speakers. She may, however, assess the form of presentation of those arguments. On the one hand, she can take into account the "dialectical performance" of the speakers, that is, the quantity, quickness, and smoothness of rebuttals to ostensive counter-evidence presented by rival

\footnotetext{
${ }^{28}$ See e.g., John Hardwig, "Epistemic dependence," Journal of Philosophy, 88 (1985), 693-708; Tyler Burge, "Content preservation," Philosophical Review, 102 (1993), 457-88; Scott Brewer, "Scientific expert testimony and intellectual due process," Yale Law Journal, 107 (1998), 1535-681.

${ }^{29}$ See Alvin Goldman, "Experts: which ones should you trust?" Philosophy and Phenomenological Research, 63 (2001), 85-111; David Matheson, "Conflicting experts and dialectical performance: adjudication heuristics for the layperson," Argumentation, 19 (2005), 145-58; David Coady, "When experts disagree," Episteme, 3 (2006), 68-79; and Thomas Christiano, "Rational deliberation among experts and citizens," Deliberative Systems, eds. J. Parkinson and J. Mansbridge (Cambridge: Cambridge University Press, 2012), pp. 27-51.
} 
speakers. ${ }^{30}$ If, for example, $E_{1}$ presents an ostensive defeater whenever $E_{2}$ offers evidence for her conclusion, while $E_{2}$ rarely manages to offer a rebuttal to $E_{1}$ 's evidence, the layperson has good reasons for placing greater trust in $E_{1}$. On the other hand, she can take into account the speakers' receptivity to new information, that is, the disposition to consider seriously new ostensive evidence and to reconsider ostensive evidence in light of new findings. ${ }^{31}$ If, for example, $E_{1}$ provides more charitable responses to $E_{2}$ 's opinions, affords fairer opportunity for $E_{2}$ to express her views, and expresses greater interest in $E_{2}$ 's ostensive evidence, there are good reasons for attributing to $E_{1}$ a greater open-mindedness and, thus, a greater epistemic credibility. ${ }^{32}$

The second source of evidence pertains to biases and distorting interests that might lie behind the claims of a putative expert. If a layperson possesses good evidence for such a bias in $E_{1}$ (stemming, for example, from economic interests, extreme loyalties towards a specific group, sexist or racist views) and no evidence for such a bias in $E_{2}$, she has better reasons for giving credence to $E_{2}$. This idea is, as Alvin Goldman points out, supported by common sense and experience: "If two people give contradictory reports, and exactly one of them has a good reason to lie, the relative credibility of the former is seriously compromised." 33

The third source of evidence consists in track records of putative experts' cognitive successes: The better a person's track record, the greater the likelihood of her having correct answers to current questions. ${ }^{34}$ At first glance, this suggestion is puzzling, for it seems that in order to use past track records to assess the credibility of a putative expert with respect to a domain of expertise $\mathrm{E}$, the layperson must possess expert knowledge about E herself. However, this is not necessarily true: Many statements pertaining to $\mathrm{E}$ are epistemically inaccessible for laypersons at a certain point in time, but become accessible later on. Consider the following claim: "Introducing a green zone in the city center will reduce particulate matter pollution (PM)." Laypersons at time $t_{0}$ may not be in a position to determine the credibility of this claim. However, at time $t_{1}$, one year after a green zone has been put into practice, they may ascertain its credibility by checking whether the average monthly PM rate has dropped. ${ }^{35}$

The fourth source of evidence stems from the cognitive capacities of other members of the political community. First, laypersons may deliberate about the arguments presented by putative experts, reciprocally fill gaps in their knowledge about the relevant area, and collectively uncover fraudulent claims. ${ }^{36}$ Second,

\footnotetext{
${ }^{30}$ Goldman, "Experts: which ones should you trust," p. 95.

${ }^{31}$ See David Matheson, "Conflicting experts and dialectical performance," pp. 151-3.

${ }^{32} \mathrm{On}$ the merit of open-mindedness for the pursuit of knowledge see also James A. Montmarquet, "Epistemic virtue," Mind, 96 (1987), 482-97.

${ }^{33}$ Goldman, "Experts: which ones should you trust," p. 104.

${ }^{34}$ See ibid., p. 106.

${ }^{35}$ We owe this example to an anonymous referee.

${ }^{36}$ See John Dryzek and Christian List, "Social choice theory and deliberative democracy: a reconciliation," British Journal of Political Science, 33 (2003), 1-28, at p. 10.
} 
laypersons can appeal to "meta-expert agreement," for example, the fact that the vast majority of putative experts regarding $E$ side with $E_{1}$, rather than her competitor $E_{2} \cdot{ }^{37}$ Third, they can make use of what Thomas Christiano calls "overlapping understanding" and explains as follows: "[S] uppose P knows about intellectual disciplines $a, b$, and $c$, and $\mathrm{Q}$ knows about disciplines $b$, c, and $d$. Their knowledge overlaps at $b$ and $c$. This overlap allows $\mathrm{Q}$ to understand some of $a$ because $\mathrm{P}$ can translate the ideas of $a$ into $b$ and $c$. Now suppose that $\mathrm{R}$ has expertise $c, d$, and $e$ and $\mathrm{S}$ has $d, e$, and $f \ldots . \mathrm{S}$ and $\mathrm{P}$ do not overlap at all. ... Despite this, S's knowledge may constrain P ... through the intermediaries Q and R." 38 Thus, even if a member of the political community is unable to directly assess the truth-value of claims that lie outside her domain of expertise, she may do so indirectly by relying on intermediaries whom she trusts and who translate the relevant content and make it intelligible to her.

The arguments from social epistemology show that liquid democracy does not need to rely solely on each and every individual's solitary capacity to select competent experts. Instead, it can make use of the fact that individuals are connected in a whole system of delegative relationships where the evaluation of experts can turn into a collective enterprise. Goldman's sources of evidence thereby mirror the features of a "reputation system" based on ranking and rating which is seen as an important condition for a functioning collective epistemic system as discussed in the literature on collective intelligence. ${ }^{39}$ As Gloria Origgi argues, given an overwhelming informational environment with a multitude of competing sources, such as the World Wide Web (and, we could add, such as a liquid democracy), successful epistemic practice becomes possible if we gain access to information about how others value and rate things. Not all crowds are wise, but we can argue with Origgi that they become wiser where online reputation systems "collect, distribute, and aggregate information about participants' past behavior." ${ }^{40}$ The claim that we can find the right experts for the right job thus gains further plausibility, since the epistemic practice of processing information through online rankings and ratings is already a part of many people's daily routine, for example when selecting from a range of book-sellers on Amazon. ${ }^{41}$

\footnotetext{
${ }^{37}$ Ben Almassi, "Climate change, epistemic trust, and expert trustworthiness," Ethics and the Environment, 17 (2012), 29-49, at p. 37 and Goldman, "Experts: which ones should you trust?" p. 97.

${ }^{38}$ Christiano, "Rational deliberation among experts and citizens," p. 38.

${ }^{39}$ See Gloria Origgi, "Designing wisdom through the web," Collective Wisdom, eds. H. Landemore and J. Elster (New York: Cambridge University Press, 2012), pp. 38-55.

${ }^{40}$ Origgi, "Designing wisdom through the web," p. 49.

${ }^{41}$ Interestingly, recent survey-based evidence suggests that people using the Internet as a source of information are more likely to develop issue-specific knowledge than those who rely on TV, newspapers, or the radio; see S. Mo Jang and Yong Jin Park, "The internet, selective learning, and the rise of issue specialists," First Monday, 17 (2012), available at <http://dx.doi.org/10.5210/ fm.v17i5.3888>.
} 
Another argument from collective intelligence goes one step further: Even if reasoned expert selection fails, liquid democracy could still plausibly be expected to be epistemically superior to representative democracy, since it does not only mobilize the expertise of the few, but also brings the wisdom of the many to bear on a decision. The theoretical foundation for this claim can be found in Scott Page's work on cognitive diversity. ${ }^{42}$ The more diverse individuals' ways of representing situations and problems, of categorizing or partitioning perspectives, of generating solutions to problems and of inferring cause and effect, the better the community at developing predictive models and solving problems. He provides experimental evidence and mathematical proof for a "Diversity Trumps Ability Theorem" and a "The Crowd beats the Average Law." The former states that under certain conditions, "a randomly selected collection of problem solvers outperforms a collection of the best individual problem solvers." 43 The latter holds that "given any collection of diverse predictive models, the collective prediction is more accurate than the average individual prediction." ${ }^{44}$ Relating his own findings to democratic decision-making, Page explicitly acknowledges that individuals may indeed have poor incentives to invest in improving their own predictive models in order to competently decide on policies. He then argues that this is not necessary for good decisions, since the lack of individual ability can be compensated by cognitive diversity: "An effective democracy ... may depend as much on its citizens' having diverse predictive models as on their having accurate predictive models." 45 Thus, liquid democracy is likely to produce better decisions even if expert selection fails. With its greater openness to participation, liquid democracy makes it more likely that a large, cognitively diverse group of people provide input to each decision.

Finally, since the skeptical worries concern the capacities of real members of a political community, empirical research on voter competence in direct democratic decision-making can be instructive. Direct democratic institutions are often confronted with skepticism, since a range of widely cited studies show that the average voter is poorly informed and lacks coherent and stable political preferences and beliefs. ${ }^{46}$ However, these findings have been countered with several more optimistic responses. One response has been to bite the bullet and accept the verdict of the poorly informed voter, only to then show that the

\footnotetext{
${ }^{42}$ Scott Page, The Difference (Princeton, NJ: Princeton University Press, 2007).

${ }^{43}$ Scott Page, The Difference, p. 162. The four conditions are that the problem is difficult (which is typical for most policy decisions), that all problem solvers have at least some ability to solve the problem (in technical terms, they need to be able to recognize a local optimum), the group is diverse to the extent that some problem solver can find improvement (i.e., local optima are different but they intersect in only one global optimum), and the set of problem solvers must be sufficiently large.

${ }^{44}$ Page, The Difference, p. 209.

${ }^{45}$ Ibid., p. 347.

${ }^{46}$ See most prominently: Philip E. Converse, "The nature of belief systems in mass publics," Critical Review, 18 (2006), 1-74 (originally published 1964), and John R. Zaller, The Nature and Origins of Mass Opinion (New York: Cambridge University Press, 1992).
} 
uninformed nonetheless successfully use heuristics to make competent choices, that is, they are capable of predicting the outcomes of their choices and of evaluating whether they are in line with their preferences. Using heuristics allows individuals to keep the challenges of information processing in a complex environment within manageable boundaries. The punch line in this literature is: Yes, information is costly, yes, people are poorly informed, but observational and experimental evidence tell us that this does not matter for the quality of their decisions. ${ }^{47}$ A prominent heuristic is to rely on cues from the more informed. Experiments show that in the absence of shared interests (e.g., when individuals are from different social groups), it becomes crucial to introduce institutions such as penalties for lying and threats of verification to make it unlikely that cue-givers will use their position to deceive and manipulate cue-takers. ${ }^{48}$ This reiterates the importance of a functioning reputation system discussed above, though from a different angle.

A second response has been to dispute whether the lack of information people display when answering factual questions about politics in a survey has any connection to the information they need to perform their tasks in direct democratic polls, ${ }^{49}$ and to call for paying closer attention to the importance of how we measure "ignorance." For example, Jason Barabas et al. provide a typology of knowledge and show that the answers to substantive research questions (e.g., whether education affects political knowledge) differ depending on whether we measure knowledge as knowledge about the rules of the game (affected by education) or as policy-specific knowledge (unaffected by education)..$^{50}$ Finally, whereas findings about ignorance are mostly based on US voters, research that compares cantons in Switzerland has shown that increased possibilities for participation in fact lead to citizens being better informed. ${ }^{51}$ In addition to theoretical arguments from social epistemology and collective intelligence, empirical research on direct democratic decision-making thus provides further ground for optimism with regard to the practicality of liquid democracy. It shows that reasoned choice is not dependent on the level of

\footnotetext{
${ }^{47}$ For experimental and observational evidence, see e.g.: Arthur Lupia, "Shortcuts versus encyclopedias: information and voting behavior in California insurance reform elections," American Political Science Review, 88 (1994), 63-76; Lupia and Mathew D. McCubbins, The Democratic Dilemma (New York: Cambridge University Press, 1998); and Paul M. Sniderman, Richard A. Brody, and Philip E. Tetlock, Reasoning and Choice (Cambridge: Cambridge University Press, 1991). Experiments by Lau and Redlawsk provide nuance to these findings, cautioning that the politically sophisticated make better use of heuristics than the less sophisticated, see Richard R. Lau and David P. Redlawsk, "Advantages and disadvantages of cognitive heuristics in political decision making," American Journal of Political Science, 45 (2001), 951-71.

${ }^{48}$ Cheryl Boudreau, "Making citizens smart: when do institutions improve unsophisticated citizens' decisions?” Political Behaviour, 31 (2009), 287-306.

${ }^{49}$ Ibid., p. 291.

${ }^{50}$ Jason Barabas, Jennifer Jerit, William Pollock, and Carlisle Rainey, "The question(s) of political knowledge," American Political Science Review, 108 (2014), 840-55.

${ }^{51}$ Matthias Benz and Alois Stutzer, "Are voters better informed when they have a larger say in politics? Evidence for the European Union and Switzerland," Public Choice, 119 (2004), 31-59.
} 
information as long as more motivated individuals act as cue-givers and are prevented from lying through a functioning reputation system. Furthermore, in the long run increased possibilities for participation may actually set incentives for more members to become better informed.

\section{PROBLEMS AND MODIFICATIONS OF THE BASIC MODEL OF LIQUID DEMOCRACY}

However, even if members are well-informed, or make at least good use of heuristics, liquid democracy still encounters the challenges of (1) avoiding to recreate representative democracy's problem of two classes of citizens, though in a different way (the problem of unequal voting power) and (2) achieving consistency across the whole set of decisions being made across different policy areas (the problem of policy-inconsistency). Neither problem arises to the same extent in representative democracy. In order to maintain our argument that liquid democracy is superior to representative democracy, modifications to the basic model are therefore in order.

\section{A. The Problem of Unequal Voting Power}

The problem of unequal voting power is a direct consequence of allowing members of a political community to choose freely whether to cast their vote on an issue themselves or whether to delegate it to a representative. Let us reconsider the example given in section I. A decided to delegate her vote on whether to authorize planting genetically enhanced corn to $B$, a renowned expert on this matter. It is plausible that not only $A$, but several other members of the community also delegate their votes to $B$. After all delegations have been made and the time for casting the vote has come, $B$ can cast 450 votes. Consider now that unlike $A$, individual $C$ has chosen to vote himself. $B$ and $C$ now cast their vote in the final decision on genetically enhanced corn, the "slight" difference being that $B$ casts 450 votes, whereas $C$ casts one vote.

The example shows that liquid democracy runs the risk of reproducing a problem of representative democracy, though in a different way. Rather than dividing the political community into a class of ordinary citizens without and a class of representative elites with decision-making power for the duration of a whole legislative period, liquid democracy divides the decision-making body in a given policy area into ordinary members with one vote and members with $2+\mathrm{N}$ votes. ${ }^{52}$ This problem does not occur to the same extent in representative democracy where each citizen has one vote when it comes to selecting representatives and where each representative has one vote when deciding in

\footnotetext{
${ }^{52}$ See also Ford, "Delegative democracy," p. 3.
} 
parliament. This inequality of voting power may provide counter-incentives for ordinary members to participate directly in collective decision-making. Since their political resources to influence decisions are marginal compared to those of "super-representatives" with thousands of votes, ordinary members have little reason to directly vote on policy issues. Thus, a conflict comes to light between the direct democratic component and the flexible delegation component of the basic model. However, if one holds on to the idea that all members should be entitled to directly vote on policy issues, it seems necessary to qualify the flexible delegation component.

\section{B. The Problem of Policy-Inconsistency}

The beauty of liquid democracy is that it gives individuals the free choice on whether or not to delegate their vote, and it does so for policy areas individually. However, on the downside, this flexible and issue- or area-specific delegation implies that the composition of the decision-making body in each policy area varies. Whereas non-delegates with just one vote may have incentives to form alliances within a policy-area to rival the voting power of popular delegates with many votes, there are no comparable incentives for forging alliances across policy-areas. This poses severe challenges to the quality of the overall policy output of a given democracy since all policy decisions are inherently connected through a common and public budget in virtue of which measures in one policy field impact on the resources available in another. Furthermore, even if sufficient resources for all measures were available, there might be substantive contradictions between decisions taken in different areas. In the absence of a coordinating body of decision-makers with oversight, those contradictions are doomed to remain unnoticed until the later stage of policy implementation.

By contrast, representative party democracy is strong at bundling together solutions to societal problems from different policy areas—and also trading them against each other, if necessary. First, at the beginning of the electoral phase, parties negotiate internally over the programmatic policy bundle they want to offer to voters. Each electoral program is thus the result of negotiating goals and measures to reach these goals across different policy areas. Second, during the inter-electoral phase (i.e., the phase between representative elections) parties put forward programs for governing that have to get the support of the parliament where the same people are deciding on all policy areas, thereby becoming necessarily aware of the interconnectedness and potential trade-offs between individual decisions. In liquid democracy, there is no distinction between electoral and inter-electoral phases, since new issues can continuously be brought onto the agenda. Parties as coordinating mechanisms are superfluous since members of the community either participate directly or delegate their votes on the basis of individual relationships with their delegate. Finally, the principle of instant recall ensures that the group of people dealing with issues in a given area 
may change composition between decisions. To be sure, any method of aggregating preferences where more than two alternatives are involved is potentially bedeviled by a problem of cycling collective preferences. ${ }^{53}$ In that regard, liquid democracy is no better or worse than any other collective decision-making procedure. However, whereas in a representative democracy, at least the preferences to be aggregated are consistent across policy areas since the same parliamentarians vote on all issues (even if the social preference may cycle), in liquid democracy not even the preference input is consistent across policy area because different people decide. As a result, liquid democracy can be expected to display inferior performance in its public-policy output.

\section{Deliberating Trustees and an EXecutive with Oversight-TOWards A SOLUTION}

We suggest that these problems can be ameliorated by combining the basic model of liquid democracy with three components: (1) a trustee, rather than a mere delegate model of representation, (2) elements of deliberative democracy, and (3) an executive with oversight.

We have seen that participatory incentives for ordinary members with just one vote will be minor if there are "super-representatives" with hundreds of votes in the same policy forum. However, what if, once delegation has happened, there was the additional option of deliberating on possible answers to the societal problem at stake before casting votes? ${ }^{54}$ In that case, even an ordinary member with a single vote could bring forward the decisive argument that may convince a representative with 450 votes. Rather than merely aggregating votes once delegation has happened, there should be a phase were decision-makers engage in giving reasons for why they intend to vote in favor or against a proposal. Including a deliberative phase between delegation and voting thus gives members with just one vote the chance to make a difference.

However, including a deliberative phase implies that voting intentions have to be revisable in principle. Representatives therefore need to have some degree of discretion and independence. Including the possibility for deliberation thus has important implications for how we conceive the representational role of the delegates. In her seminal analysis of the concept of representation, ${ }^{55}$ Hanna Pitkin

\footnotetext{
${ }^{53}$ The mathematical foundation for the problem of cyclical social preferences is Kenneth Arrow's impossibility theorem, famously used to argue that democratic rule is irrational by William Riker in Liberalism Against Populism (San Francisco: W. Freeman, 1982). The empirical relevance of the theorem, however, has been disputed; see Gerry Mackie, Democracy Defended (Cambridge: Cambridge University Press, 2003).

${ }^{54}$ In keeping with the standard definition, we understand political deliberation as a rational and egalitarian type of communicative contestation about policies where all participants are required to justify their interests to others, take into account their respective views, and revise their positions in light of better arguments (see Dryzek, Deliberative Democracy and Beyond, pp. 47-50.

${ }^{55}$ Hanna F. Pitkin, The Concept of Representation (Los Angeles: University of California Press, 1967).
} 
argues that political representation lies on a continuum between the extreme poles of mechanic execution of the principals' instructions ("delegate") and complete independence ("trustee"). It is defined by Pitkin as follows: "The representative must act in such a way that, although he is independent, and his constituents are capable of action and judgment, no conflict arises between them. He must act in their interest, and this means that he must not normally come into conflict with their wishes." ${ }^{\prime 6}$ In light of the problem of unequal voting power, liquid democracy needs representatives that lean enough towards the independence side of the continuum and have discretion to change their voting intention on the basis of justified reasons presented to them within a deliberative stage. They may, however, do so only if they consider such a change to be in the best interest of the individuals who delegated their votes to them in the first place. Delegates thus need not merely cast the vote their principals would and could have cast themselves, but have discretion to take into account new arguments presented during deliberation and update their voting intentions accordingly. However, at the same time, "the principal's wishes must be potentially there and potentially relevant," 57 and liquid democracy ensures this through the principle of instant recall. If the principals become aware that there is a conflict between their interests and the actions taken by the representative, they can withdraw their delegated vote.

However, including a deliberative phase does not only ameliorate the problem of unequal voting power. Following David Miller, John S. Dryzek, and Christian List, it also helps to reduce the structure of political conflict to one, rather than several issue dimensions, thereby preventing preference cycles and ensuring the transitivity of collective preferences. ${ }^{58}$ In addition, it opens up a possibility of linking individual decisions to others within the same policy area, thus ameliorating the problem of policy-inconsistency. This shows why it might be more advantageous to structure relationships of delegation by policy area, rather than by individual topic. Only the former offers the possibility to connect individual decisions within the same policy area. For example, when discussing a reform that shortens the years of high school education, it seems advisable to consider the wider implications for the quality of higher education, since universities now have to deal with a greater number of potentially less well-prepared entrants. The decision-makers should therefore simultaneously address measures to support universities in dealing with this challenge. At the same time, only delegation by policy area lowers information costs compared to full-scale direct democracy. If I still need to engage with every single decision being taken in order to decide on a case-by-case basis whether and to whom to

${ }^{56}$ Ibid., p. 166.

${ }^{57}$ Ibid., p. 155.

${ }^{58}$ David Miller, "Deliberative democracy and social choice," Political Studies, 40 (\#5) (1992), 54-67; Dryzek, Deliberative Democracy and Beyond, pp. 38-42; and Dryzek and List, "Social choice theory and deliberative democracy," pp. 7-27. 
delegate my vote, this will not be much easier than directly voting on all issues myself. However, once I have established that $E$ is an expert on education policy and have delegated my vote to her for all issues on the agenda that are tagged as belonging to this policy area, I can retreat from following this policy-area more closely (apart from occasionally checking whether her voting behavior corresponds to my interests).

However, as argued above, coherent public policy output of the democratic political system requires not only coordination of decisions taken within one policy-area but also across policy-areas. In order to address this challenge, we suggest to strictly limit the role of liquid democracy to legislative decision-making. Liquid legislatures are then to be accompanied by a democratically elected executive serving a fixed term that does not blindly implement, but also reviews laws in terms of financial viability and overall consistency. When financial trade-offs and/or inconsistencies between laws from different areas are detected, the executive should return the affected legislative proposals to the area-specific forums. It should finally have the competence to initiate and moderate negotiation processes between different areas for reaching package deals. Importantly, however, the executive should not be entitled to veto laws from a substantive perspective (i.e., on the basis of disagreeing for some reason or another with the content of the law), but only from the perspective of financial resources and inconsistencies between individual laws from different policy areas. In liquid democracy, connections between policies are thus the end product of a bottom-up process (where people's preferences are aggregated at the level of individual polices) rather than being proposed in a top-down manner by political elites, as is the case in representative democracies.

\section{CONCLUSION}

This article has justified liquid democracy on the basis of arguments from normative democratic theory. We have argued that collective decision-making according to the basic model of liquid democracy is more epistemically reliable and more egalitarian than representative democracy. Drawing on arguments from social epistemology, and research on collective intelligence and voter competence in direct democratic decisions, we have shown that there are good reasons to be optimistic that ordinary members of a political community can indeed perform their liquid democratic tasks.

We have further addressed two problems of the basic model of liquid democracy: the problem of unequal voting power and the problem of policy-inconsistency. We have therefore suggested three modifications: (1) combining the basic model with a trustee, rather than a mere delegate model of representation; (2) requiring decision-makers to adhere to deliberative norms; and (3) balancing liquid decisionmaking in legislatures with an executive that reviews the fiscal feasibility of policies and moderates package deals between proposals from different policy areas. 
Naturally, this discussion of problems and potential solutions does not exhaustively address the many issues that should be taken into consideration when putting liquid democracy into practice. However, fleshing out all details involved in putting liquid democracy into practice was beyond the scope of this article. We have aimed to provide a normative justification of liquid democracy to inspire further discussion on this previously neglected type of collective decision-making. We hope that future theoretical work will now address questions such as: Should the executive consist of a president with an appointed cabinet? How exactly would a budgeting system work under liquid democracy? How should the agenda-setting process be structured? How should the reputation and ranking system be designed?

Finally, our article has justified liquid democracy at the systemic level, comparing it to representative democracy as the best systemic alternative. Currently, liquid democratic decision-making is emerging on smaller scales as a decision-making procedure applied within political parties or institutions of local government. ${ }^{59}$ Future empirical research should therefore address the interactions between liquid decision-making and an overall representative democracy. We hope that these works will benefit from the clarification and justification of the basic model of liquid democracy we have sought to provide in this article.

${ }^{59}$ See the discussion on "Liquid Friesland" (Friesland being a county in Northern Germany) by Fiorella De Cindio and Stefano Sortone, "Experimenting liquid feedback for online deliberation in civic contexts," Electronic Participation: 5th I.F.I.P. W.G. 8.5 International Conference Proceedings, ed. M. Wimmer, E. Tambouris, and A. Macintosh (Heidelberg: Springer 2013), pp. 147-58. 